\title{
Research on the Effects and Influencing Factors of Social Work Profes- sional Policy in China
}

\author{
Bin Tu Xue Bai* \\ School of Public Administration, Guangdong University of Foreign Studies, Guangzhou, China.
}

\begin{abstract}
Social work professional are an indispensable force for building a harmonious society and strengthening and innovating social governance. In order to promote the development of social work professional, some policies about social work professional have been issued in China. This article attempts to explore the effect and influencing factors of social work professional policy. Finding as followings: social workers' education degree, professional titles and the number of female social workers shows a growing trend. There is still a gap in the total number of social workers and professional compared with developed countries. The proportion of social workers below 46yrs. in national social workers has dropped year by year. The rationality of the regional structure of social work professional needs to be improved. The main causes are: There are lower professional awareness and social recognition to social worker in the society. The social worker professional' salary system is not perfect, and the organization management capabilities need to be improved. The suggestions are: Expand the communication platform of social work professional' team construction by informatization. Strengthen publicity and enhance social awareness of social work professional. Implement salary incentive measures and strengthen system guarantees.
\end{abstract}

Keywords: social work; professional; policy; effect; influence

*Corresponding Author: 404738865@qq.com

DOI: $10.36012 /$ ems.v1i2.1835

\section{Introduction}

ocial work professional is specialized personnel who have certain professional knowledge and skills in social work, and directly provide social services in the fields of social welfare, social assistance, poverty alleviation, charity, community construction, marriage and family, mental health, disability rehabilitation, employment assistance, employee assistance, crime prevention, drug control and rehabilitation, correction and assistance, emergency response, and mass culture. Social work professional are an indispensable force for building a harmonious society and strengthening and innovating social governance. Vigorously strengthen the construction of professional for social work, which can play a role in enhancing community service functions, improving the autonomy of community residents, promoting the construction of harmonious communities, implementing social polici es, innovating public service approach, and satisfying the increasing demand for the public's social services.

In order to promote the development of social work professional, the "Opinions on Strengthening the Construction of Social Work Professional" was issued in 2011 in China. The purpose is mainly to adapt the number, structure and quality of the social work professional professional team to the needs of building a harmonious society and to meet the public's growing service demand. The main measures include that the professional quality and professional ability of social service personnel are greatly improved through large-scale professional training, the scale of social work professional is gradually expanded by deepening the social work professional education reform and improving the social work professional training system, the awareness and recognition of social work profes 
sional can be improved by strengthening theoretical research and popularization of social work professional, Gradually establish a system of policies and regulations for the training, selection, use, flow, evaluation, and incentives of social work professional. After the implementation of the policy and development of social worker professional nearly 10 years of, how has the development of social worker professional been? How has the effect of the policy been? What factors have affected the realization of the social work policy effect? What kind of path can better promote the development of social worker professional? This article attempts to answer these questions.

\section{Effect analysis of social work professional policy}

\subsection{Changes in the structure of social workers' edu- cation and the structure of professional title}

2.1.1 Changes in the structure of social workers' education degree

Social work education has entered a stage of rapid development in China, majors in social work have appeared in major colleges and universities in China, and the enrollment scale has been rapidly expanded since 2000. The education degree of social worker professional has also been continuously improved. Since Renmin University of China first established the postgraduate major in social work in 2004, more and more universities and institutions have cultivated graduate programs for social work professional, and a doctoral education program for social work has begun. Renmin University of China as the first batch of colleges and universities to offer doctoral education in social work. These colleges and universities lead the development of social work education. Social work professional have upgraded their academic levels, and social work professional who graduate with high degrees each year are also on the rise. It shows that the educational level of social workers is increasing year by year in Table 1 and Figure 1 the number of junior colleges, undergraduates has increased by nearly one hundred thousand from 2010 to the end of 2018, and the number of social workers with colleges and undergraduates and above is increasing year by year. It can be seen from figure 1 that the proportion of social workers with a college degree and a bachelor's degree or above accounted for the proportion of all social workers from 2010 to 2018 has been increased, the proportion of college students increased by $10.9 \%$, and the proportion of bachelor students and above increased by $7.3 \%$. The overall proportion of social workers is increasing year by year. The education qualifications of the social work professional team showed overall steady development.

2.1.2 Social worker with professional title have increased year by year

Social Work Qualification Examination has started Since 2008, the number of professional titles obtained by social work professional has been steadily increasing, The number of social workers with medium-grade professional title increased from 5,176 in 2010 to 23,582 in 2018 , and the number increased by $355.6 \%$. The number of social workers with junior title increased from 6,724 in 2010 to 57,447 in 2018, and the rate increased by $754.4 \%$ (see Table 2). It can be seen from Chart 2 that the number of social workers and social workers who have obtained certificates is on the rise. After 2015, the rising trend has obviously increased, social worker with junior title made the rapid increase in the number of it. The guidance of policies

Table 1. Changes in the educational level of social work professional

\begin{tabular}{c|c|c|c|c|c|c|c|c|c|c}
\hline & & 2010 & 2011 & 2012 & 2013 & 2014 & 2015 & 2016 & 2017 & 2018 \\
\hline \multirow{2}{*}{$\begin{array}{c}\text { Education } \\
\text { Degree }\end{array}$} & The number of college degree & 249190 & 269113 & 316330 & 380979 & 403215 & 426108 & 379398 & 407407 & 398679 \\
\cline { 2 - 10 } & The number of bachelor degree & 113316 & 126725 & 151946 & 177956 & 194878 & 220567 & 219841 & 242015 & 225441 \\
\hline $\begin{array}{c}\text { College degree accounted for the proportion of } \\
\text { all social workers }\end{array}$ & $10.60 \%$ & $11.40 \%$ & $13.10 \%$ & $14.20 \%$ & $14.50 \%$ & $15.10 \%$ & $20.40 \%$ & $20.40 \%$ & $21.50 \%$ \\
\hline $\begin{array}{c}\text { Bachelor degree and above account for the } \\
\text { proportion of all social workers }\end{array}$ & $4.80 \%$ & $5.40 \%$ & $6.29 \%$ & $6.61 \%$ & $7.03 \%$ & $7.83 \%$ & $11.84 \%$ & $12.10 \%$ & $12.12 \%$ \\
\hline
\end{tabular}

The data is from the China Civil Affairs Statistical Yearbook from 2011 to 2019. 


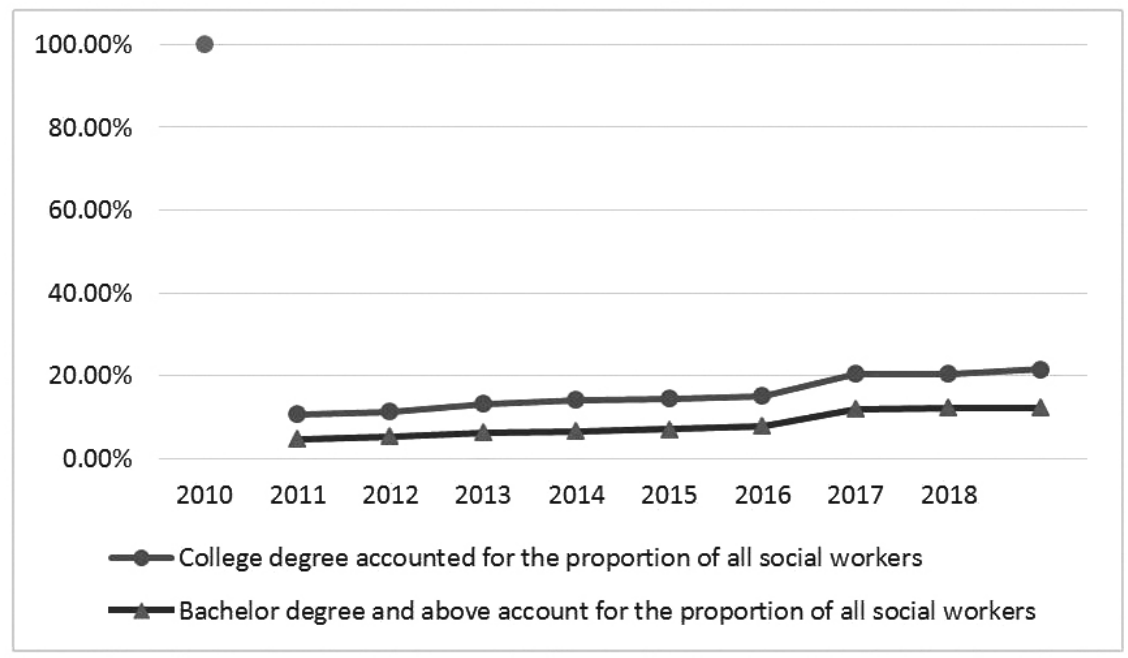

Figure 1. Shows changes in the proportion of professionally educated social work professional in all social workers and the salary incentive measures of social work organizations have jointly promoted the continuous increase in the registration rate and pass rate of social work professional in the examination. The proportion of social workers with junior title in the total social workers has increased from $0.29 \%$ to $3.09 \%$ and the proportion of social workers with medium-grade professional title increased from $0.22 \%$ to $1.27 \%$ in the

past eight years. The chart 3 shows that the proportion of social workers with junior title and social workers with medium-grade professional title in the total number of social workers has shown an increasing trend. The proportion of social workers with junior title is higher than that of social workers with medium-grade professional title, and has shown rapid growth after 2015.

Table 2. Changes in the professional qualification of social work professionals

\begin{tabular}{c|c|c|c|c|c|c|c|c|c}
\hline & 2010 & 2011 & 2012 & 2013 & 2014 & 2015 & 2016 & 2017 & 2018 \\
\hline Social workers with junior titles & 8,979 & 10,750 & 17,101 & 21,917 & 25,782 & 45,248 & 55,115 & 69,087 & 92,930 \\
\hline $\begin{array}{c}\text { Social workers with medium-grade } \\
\text { professional titles }\end{array}$ & 23,731 & 28,663 & 36,436 & 43,301 & 50,770 & 59,043 & 81,709 & 106,960 & 196,047 \\
\hline
\end{tabular}

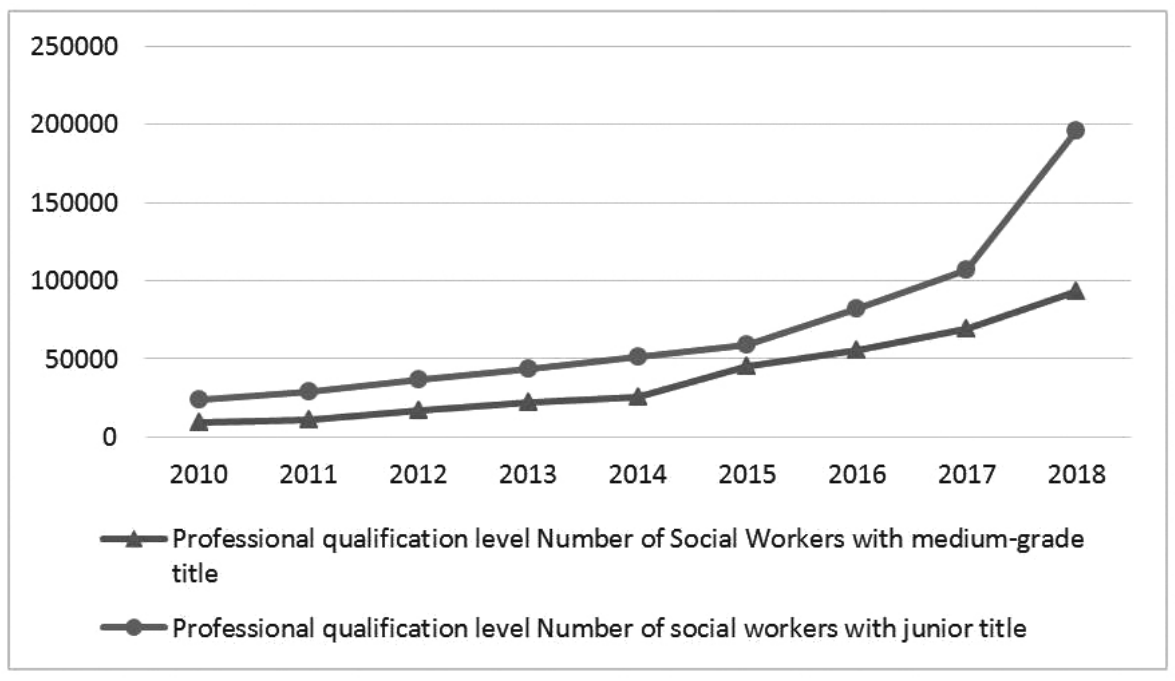

Figure 2. Changes in the professional qualification of social work professionals 


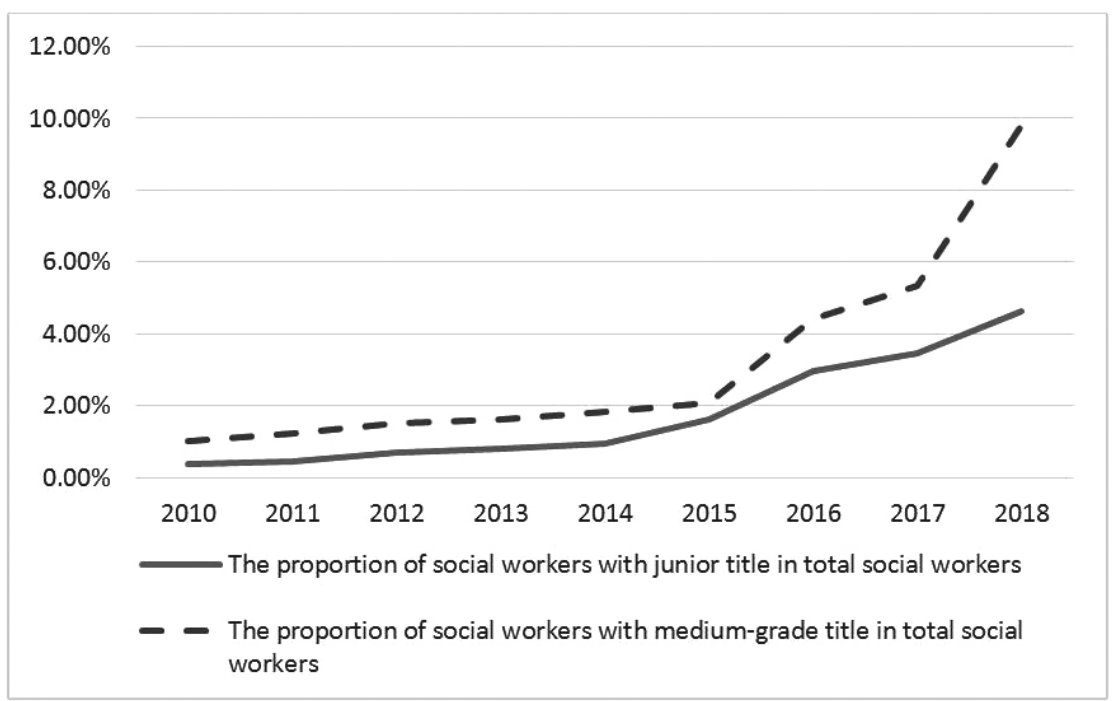

Figure 3. Shows changes in the proportion of social workers with professional title in total social workers

\subsection{Changes in gender and age of social work pro- fessional}

The development of social work is attached importance to by the central and local governments, and cultivating and developing social work professional has become an important task of government work. Through the unremitting efforts of all stratum, social work professional have continued to grow and develop. By 2018, there have been more than 2 million in the number of social workers. More and more people have joined into social work professional, among which the proportion of female social workers has also shown a steady increase. There was a significant increase in 2011 , from $15.20 \%$ of the national social workers in 2010 to $37.70 \%$ in 2011 . More and more female social workers joined, promoting more effective social work services and providing women with a variety of career choices.

The age structure of social workers has changed to some extent. It can be observed that the largest number of social workers is those aged 36-45 in chart
4, followed by those under 35 who are engaged in social work. However, the proportion of social workers in these two age groups in national social workers has dropped year by year, while the proportion of social workers aged 46-55 and over 56 has increased year by year, indicating that the proportion of young social workers entering the field is decreasing. On the one hand, in actual work, the professionalization of social work professions is low, and social awareness of social work is insufficient. As a result, the professional satisfaction of social workers at work is not guaranteed. On the other hand, the Master of Social Work does not have a high degree of recognition of the social work profession, and the current overall social recognition of social work is low. The factors such as lack of post, low salary etc. affect social workers career choice. The students majored in social lack confidence in the development prospects of the social work industry. They plan social work careers as "transitional" jobs, or engage in other industries after graduation, which is a great loss to the construction of the social work professional team.

Table 3. Changes in the age structure of social work professionals

\begin{tabular}{c|c|c|c|c|c|c|c|c|c}
\hline & 2010 & 2011 & 2012 & 2013 & 2014 & 2015 & 2016 & 2017 & 2018 \\
\hline 35 and below & 778,020 & 818,782 & 817,717 & 878,935 & 874,724 & 874,620 & 547,264 & 578,109 & 561,675 \\
\hline 36 to 45 & 899,052 & 933,487 & 969,890 & $1,046,306$ & $1,083,964$ & $1,100,177$ & 707,152 & 741,069 & 744,688 \\
\hline 46 to 55 & 467,306 & 484,934 & 521,640 & 595,299 & 629,649 & 654,115 & 460,972 & 509,504 & 527,316 \\
\hline 56 and over & 112,173 & 119,876 & 126,881 & 171,789 & 184,190 & 191,542 & 141,156 & 168,835 & 166,613 \\
\hline
\end{tabular}




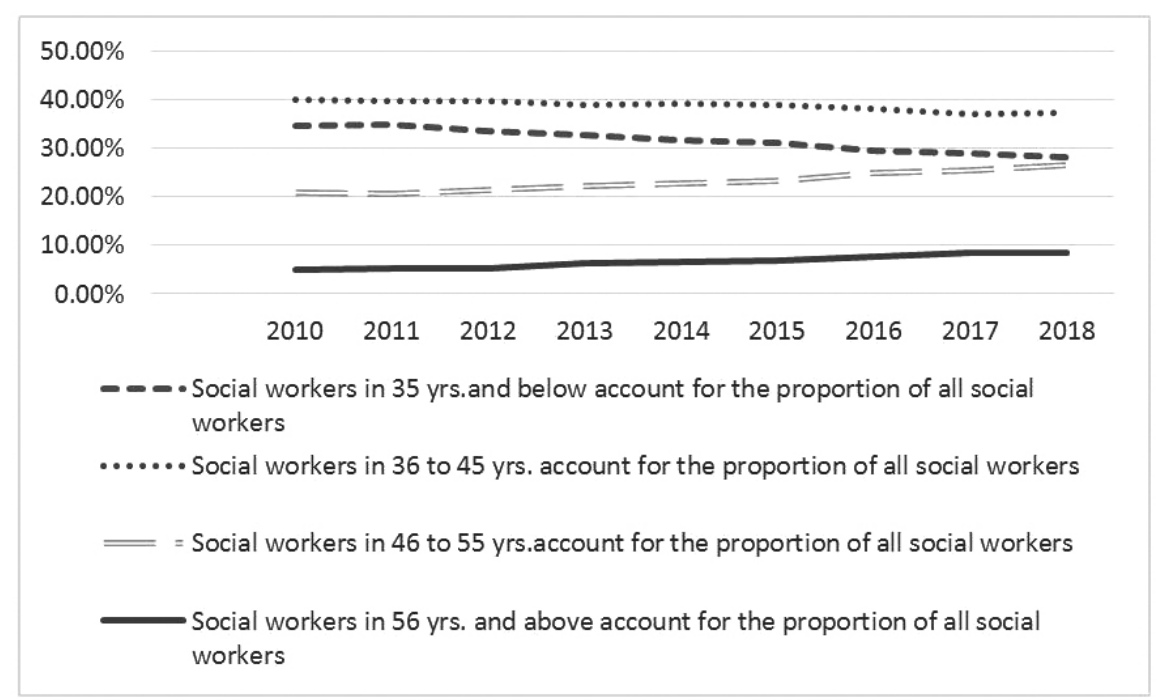

Figure 4. shows changes in social workers in different age account for the proportion of all social workers.

\subsection{There is still a gap in the total number of social workers and the number of professional}

In some countries with better development of social work professional, such as the United States, Japan and Canada, the proportion of professional social workers in the total population is $2 \%, 5 \%$ and $2.2 \%$ respectively. In Hong Kong, registered social workers account for $1.7 \%$ of the total population. According to the statistics of the Ministry of Civil Affairs, China Mainland professional social workers accounted for $0.31 \%$ of the total population by the end of 2018 . The number is far less than that of developed countries and regions. The demand of social workers in China cannot meet the need. Social work professional is the core of promoting social work, and social work plays an effective role in helping people in difficulties. Therefore, the shortage of social work professional needs to be paid more attention to.

\subsection{The rationality of the regional structure of so- cial work professional needs to be improved}

There is an unreasonable regional structure in the distribution of social work professional. By the end of 2018 , nearly 300,000 social workers with junior and intermediate professional titles had been added nationwide. Those social workers are concentrated in the eastern and southern regions, there are more than 80,000 social workers with professional title in Guangdong, more than 50,000 in Jiangsu, more than 40,000 in Zhejiang, and more than 20,000 in Beijing, Shanghai, and Shandong. However, the remote areas of the west lack social work Professional cannot be compared with the developed eastern regions.

Social work is still a new thing in the central and western regions, and it is even more unfamiliar in remote ethnic areas. One of the causes is the leaders of the local government in the western region are skeptical of social workers, lack of cooperation in actual work contacts, and have a low understanding of the professional services of social workers in the remote and poor areas.

\section{Analysis of factors affecting policy effects}

3.1 The professional allocation of social workers is unreasonable, and professional shortage and surplus coexist

As a new profession, social work is still in the development stage in China, thus there will be a shortage of social work professional, and the degree of specialization of social work professional needs to be improved. The part of the present social workers is composed of transferred administrative staff and community workers, without professional social work training, professional are lack in the process of social work services. The shortage of social work professional is more obvious in the remote district. Due to the poor overall environment of the remote district, the places and facilities for social workers to carry out professional services are also in a state of scarcity, so professional social workers who persist in service for a long time are very scarce. Secondly, because the economic development in remote areas is relatively backward, it is difficult to 
attract social workers to stay in the remote districts for development. However, a large number of social work professional graduate from colleges and universities every year, and the state attaches great importance to the cultivation of social work professional, but social work professional are not matched to the corresponding social jobs reasonably. Social work college students usually do not choose social work as their lifelong career after graduation, so the shortage and surplus of social work professional are urgent problems to be solved.

\subsection{There are lower professional awareness and so-} cial recognition to social worker in the society

The professionalization process of social work lags behind professional education, so social recognition is relatively low. On one hand the current social work as a profession in China is still a new thing, the slow development of social work in the central region and the north-west region, social work is still a little-known profession, and the process of professionalization of social work is relatively slow; On the other hand, the pace of professional education in social work has been accelerating. Since 2012, the first batch of master's degree education in social work has been carried out in China. Some schools have obtained doctoral qualifications in social work, and the professional education of social work professional has far exceeded professionalism. In the areas where social workers provide services, such as judicial correction, employment services, medical and health care, youth affairs, women's rights protection, etc., most people still do not understand its connotation, Even if social workers themselves don't understand social work before coming into the industry, there are problems such as low recognition and insufficient support for the role of social work professional, which affects the professional ability and service effect of social work professional.

\subsection{The social worker professional salary system is} not perfect, and the organization management capabilities need to be improved

The fundamental reason that affects the professional satisfaction of social work professional is the lack of a systematic social work wage system, which does not match the development of social work in the new era.

The wage level of social workers has increased compared with previous years, but it is not relatively equal to the contributions of social workers and lacks an effective incentive mechanism. It is relatively difficult to measure quantitatively and qualitatively of social work service. Social work in Guangdong Province has been developing well, and the development of social work professional is at the forefront of the country. The Guangdong Provincial Government has continuously expanded its investment in purchasing social work services, with a cumulative investment of nearly 6 billion yuan. However, there are still some problems, such as low salary, bottleneck of development and slow career promotion. According to a survey conducted by the Civil Affairs Department of Guangdong Province in $2018,51.9 \%$ of social workers choose to leave social work because their income has not reached their satisfaction. Jiaxing City adopts the "government purchase service", but the quality of service is ignored in the assessment, it is unable to achieve incentives for social work professional. The actual assessment of government purchases of services fails to highlight the linkage between the salaries of social work professional and their work abilities, and cannot actually solve the salary incentive measures, which is not conducive to the stable development of social work professional.

\section{Countermeasures and Suggestions on Per- fecting the Construction of Social Work Professional Team}

\subsection{Expand the communication platform of social} work professional team construction by informatization

4.1.1 Informatization helps social work professional link resources

The informatization of social work has innovated the development model for the construction of social work professional and the development of the industry. Social work should use the Internet flexibly, promote the transformation and upgrading of the current social work as soon as possible, and rely on "Internet+", expand the connection of resources, explore multiple ways to participate, and maximize the use of the zero-distance advantage of the Internet to achieve effective linking between social work professional and social work positions. Service resources and other information data can be shared by Informatization, analyze and understand of current situation of social work services and the industry can be helped. The develop- 
ment and operation of social work organizations can be more intuitively and conveniently understood and social work professional find jobs can be helped. New models under the Internet, such as "cloud classroom teaching" and "online training", help social work professional to link high-quality resources, convene members, initiative activity and fund-raise from the off-line to the online, and gradually use Internet media for promotion. Social work professional can receive education and training indoor, which creates a new way to improve the ability of social work professional.

4.1.2 Promotes social work professional to share experiences by informatization

Information remote technology can solve the supervision problem in remote areas in western China and areas with weak development of social work. It can be realized online meetings and online guidance services for social work by using information technology, and promote the experience sharing of social work professional. Social work professional in the remote districts can use the advanced service model and experience of social workers in Guangdong and other advanced areas, and combine local characteristics to learn from each other's strengths. The informatization of rural social work has both explicit value and invisible value. Social work professional can provide social work services to closed, scattered and remote rural areas through the network, which greatly improves the service efficiency of social work, reduces the service cost, optimizes the service mode, and benefits the vast number of rural villagers and social work professional in rural areas. The information-based social work has completely changed the way farmers obtain social helping resources, and gradually make up for the gap with urban social work. The invisible value is reflected in the development process of rural social work and plays a fundamental role. Urban social work professional and rural social work professional share work experience through the Internet link, which would improve the service scope of social work professional and expands service area.

4.1.3 A new model of social workers' development is innovated by informatization

Social work service agencies and government departments could obtain new service and management ideas from social work informatization, and explore new models for the construction of social work professional team and industry development. The application of informatization can make social work service agencies more convenient and timely, and improve service efficiency; informatization can help government departments to supervise social work service agencies and service items, and can make government decisions more convincing. The popularization of the Internet and new media has increased the social influence of social work, and has also increased the public awareness of social work professional. Informatization has also shown high-efficiency advantages in the development of social work professional, promoting outstanding deeds of social work on the web will help increase the social recognition of the social work industry and enhance the professional confidence and sense of honor of social work professional. Informatization helps social work professional to improve their services in a timely manner, with the development of new media, clients can easily use the network to supervise the services of social work professional, With the improvement of service efficiency, supervision will also promote the progress and development of social work professional and continuously improve service level and service ability.

\subsection{Strengthen publicity and enhance social aware- ness of social work professional}

4.2.1. Increase the importance of social work professional at the government level

To taking the development of social work as one of the indicators for government officials assessment and performance evaluation, truly improves the understanding, attention and support of government departments at all levels of the social work professional team. The fundamental is the professional, the key is the system. Local governments should pay more attention to social workers. Only by paying more attention and improving the treatment of social work professional can they retain social work professional and develop local social work professional in remote areas or underdeveloped areas, and it is necessary to further improve the system to support the implementation of the policy of social work professional.

4.2.2 To use traditional media to publicize social work professional

The public's poor cognition foundation for social work 
professional is one of the important factors hindering the development of social work professions. At present, the society does not know more about social work and lacks awareness of social work professional, so it is necessary to strengthen social awareness of social work as soon as possible. The propaganda department and newspaper media still have a great influence on public opinion. The power of traditional media should be given full play to. Through television and radio publicity, make all people have the opportunity to understand the social work profession, and further enhance the awareness of social work professional team. Using news media to report social work professional is the most popular, the largest range and the fastest way. Selecting news media with high credibility among the public and high level of newspapers and periodicals to introduce social work professional is conducive to improving the public's awareness of social work professional.

4.2.3 New media helps the development of social work professional

The promotion of social workers could be improved by new media including WeChat, Weibo and WeChat Official Accounts It's important to adhere to the guidance of positive public opinion, and give full play to the advantages of the rapid spread of new media, systematically publicize the policies, regulations, guidelines, objectives, tasks and main measures for the construction of social work professional, widely publicize the deeds of social work professional related to the vital interests of residents in community service, and promote the recognition and trust of community residents for social work professional. The great influence of new media in the new era is helpful to promote social work professional, publicize the typical deeds of social work professional, fully display the professional style of social work professional, and let the society know about them, support them, and effectively improve the recognition of social work professional by the public.

\subsection{Implement salary incentive measures and strengthen system guarantees}

4.3.1 Actively establish and improve social worker salary regulations

At present, in the field of social work, there is no legal system for guaranteeing the salary of social work pro- fessional. The construction of legal systems related to social work is relatively scarce, and a series of legal systems need to be improved. The law is a weapon for social work professional to protect their rights and interests. Social work professional's low wages and benefits, poor working environment and conditions, and low social status would all affect the expression of their own value. It is necessary to establish and improve social workers' salary regulation to protect their rights. Though laws, to clearly define the salary benchmarks of social work organizations, clarify the status and legal rights of social work professional at the policy level and legal regulations, standardize professional behaviors, and gradually form scientific, systematic and institutionalized legal standards for the remuneration of social work professional to promote society work professional further develops and grows.

4.3.2 Social work organizations improve the benefits and promote of social work professional

Social work organizations should determine the remuneration level of social work based on the comprehensive consideration of local economic development level and income. More importantly, it should establish a reasonable stepped remuneration system based on the professional qualifications of social workers and comprehensive, On one hand, it would attract social work professional to actively obtain professional level certificates to improve the professional knowledge of social work professional; on the other hand, it allows social work professional to stay in the social work organization and continue to grow in a space for improvement. q. Establish a career promotion mechanism for social work professional and a scientific and reasonable evaluation mechanism for social work professional.

\section{Conclusion}

Social work professional are an indispensable force for building a harmonious society and strengthening and innovating social governance. In order to promote the development of social work professional, some policies about social work professional have been issue in China. Social workers' education degree, professional titles and the number of female social workers shows a growing trend. There is still a gap in the total number of social workers and the number of professional. The proportion of social workers below 46yrs. in national 
social workers has dropped year by year. The rationality of the regional structure of social work professional needs to be improved. The main influencing factor are that social workers have low professional awareness and recognition in the society, the social worker professional' salary system is not perfect, and the organization management is not scientific. The problems can be solves as followings: Expand the communication platform of social work professional' team construction by informatization. Strengthen publicity and enhance social awareness of social work professional. Implement salary incentive measures and strengthen system guarantees.

\section{Reference}

[1] Li, YB. 2017 .Inventory of Chongqing: hierarchical and classified training to create local social work professional. China Social Work,(04):24

[2] Chen, J G.2012.Suggestions on establishing a national social work professional training base in Shenzhen. Forward Forum, (07):34-35

[3] Li, YS, Han, WR , Huang,JZ,.2011. The development of social work education in China. Social Sciences, (05): $82-90$

[4] Li, SW.2008. The development and challenges of social work in the United States and Canada. Social Work, (01): 49-51

[5] Ni, X.2013. Research on the construction of social work professional team in Baotou city. Inner Mongolia Normal University

[6] Li, SM.2017. Thoughts and suggestions on the construction of social work professionals in the capi tal's basic-level communities. Journal of Beijing Xuanwu Hongqi Amateur University, (01):48-50+65

[7] Miao, YM.2014. A survey of the cultivation of high-level young social work professional. Journal of China Youth University for Political Sciences, (04):72-76

[8] Li, DM.2016. Practical dilemma in the development of "Three districts" social work professional project in Northwest China — Based on the practice in Z county, Gansu Province. Business, (31):58

[9] Zhang, Y.2015. Exploration of the professionalization of social work professional in Jiaxing City. Oriental Corporate Culture, (22):60-61

[10] Han, XW.2015. Thoughts on the construction and management of social work professional team. Knowledge Economy, (15):16-17

[11] Yu, JJ.2015. Research on the construction of social work professional team in civil administration system from the perspe ctive of human resources development. Modern Business, (14):271-272

[12] He, HY.2013. The problems and their solutions in the construction of social work professional in Harbin.Journal of the Harbin Municipal Party School, (06):80-84

[13] Chen, JJ.2019. The adjustment strategy of Guangdong social workers' salary system from the perspective of new managerialism. Social Work and Management, (04) $89-94+101$

[14] Zhan, CF.2019. Study and implement the speech at the spirit video conference of the National Civil Affairs Work Conference in 2018. Public Welfare Times

[15] Zhou, XY.2017. Informatization helps the development of social work. China Social Work, (22): 1

[16] Shi, BN.2017. Social work urgently needs information technology to help. China Social Work,(22):27-28

[17] Bai, Y.2011. Exploring the path of promoting the development of rural social undertakings with informatization. Journal of Changchun University of Science and Technology (Social Science Edition), (12):10-12.

[18] Lai, XY.2017. Put the wings of informatization on social work. China Social Work, (22):1.

[19] Li, ZB.2006. Thoughts on building a new socialist countryside. Consultation Forum, (05):6-8.

[20] Wang, SB.2014. Introduction to social work (Third Edition) . Beijing: Higher Education Press: 11.

[21] Xu, YJ.2018. Research on the welfare and security in the construction policy of social work professional. Modern Business, (33):85-88.

[22] Wang, SX.2018. The professional image, public attitudes and reshaping paths of social work professional—Based on a survey of 12 communities in district H. Central China Normal University.

[23] Tian, Y.2018. Research on the brain drain of social work professional- Taking $\mathrm{N}$ community in Xi'an as an example. Northwest University.

[24] Shao, YC.2013. Longwan district, Wenzhou, Zhejiang: three measures to promote the construction of social work professional. Social Welfare, (12):51-52.

[25] Kong, FX.2017. Research on the construction of Guangxi social work professional team under the background of targeted poverty alleviation. Reform and Opening (Social Observation), (09):61-63.

[26] Yuan, GL.2015. Development and enlightenment of social work legislation. Social Welfare, (09):46-49.

[27] Zhou, Y.2015. The current situation and countermeasures of the construction of social work professional in Anhui province. Journal of Hefei University (Social Science Edition), (03):33-36. 